\title{
One-step Electrochemically Modulated Synthesis of Reduced Graphene Oxide-Silver Nanocomposites as Efficient Nonenzymatic $\mathrm{H}_{2} \mathrm{O}_{2}$ Sensor
}

\author{
Su-Juan Li ${ }^{*}$ Jing-Chao Zhang, Juan Li, Wen-Tian Wang, Rui-Ting Liu \\ Henan Province Key Laboratory of New Optoelectronic Functional Materials, College of Chemistry \\ and Chemical Engineering, Anyang Normal University, Anyang, 455000, Henan, China. \\ *E-mail: lemontree88@163.com
}

doi: $10.20964 / 2017.06 .61$

Received: 13 March 2017 / Accepted: 29 April 2017 / Published: 12 May 2017

\begin{abstract}
In the present work, one-step electrochemical method was utilized to synthesize reduced graphene oxide-silver nanoparticles (RGO-AgNPs) composites modified electrode. By modulating the electrodeposition potential, uniform and highly dispersed AgNPs were deposited onto RGO surface, the morphology of which was characterized by scanning electron microscopy (SEM). Electrochemical impedance spectroscopy (EIS) and cyclic voltammetry (CV) were used to investigate the electrochemical properties of this RGO-AgNPs modified electrode. When the resultant RGO-AgNPs composites were employed in fabricating a nonenzymatic $\mathrm{H}_{2} \mathrm{O}_{2}$ sensor, good electrocatalytic activity characterized with low over-potential and large current response was found for $\mathrm{H}_{2} \mathrm{O}_{2}$ reduction. The proposed sensor also exhibited excellent analytical parameters for amperometric detection of $\mathrm{H}_{2} \mathrm{O}_{2}$, such as rapid response time, wide linear range, high sensitivity and selectivity, low detection limit, acceptable reproducibility and stability. This work shows prospects for fabricating high-performance electrochemical sensors.
\end{abstract}

Keywords: Electrodeposition; Reduced graphene oxide; Ag nanoparticles; Hydrogen peroxide

\section{$\underline{\text { FULL TEXT }}$}

(C) 2017 The Authors. Published by ESG (www.electrochemsci.org). This article is an open access article distributed under the terms and conditions of the Creative Commons Attribution license (http://creativecommons.org/licenses/by/4.0/). 